\title{
Comparison of Some Medicinal Plants and Macrofungi Essential Oil Components for Antimicrobial Activity against the Human and Fish Pathogens
}

\author{
Nejdet Gültepe ${ }^{1 *}$, Somia M.I. Bufrag ${ }^{2}$, Ibtesam R.A. Abughadyra ${ }^{3}$, \\ Kamla A.O. Mohammed ${ }^{2}$ and Saleh B.A. Alkhunni, ${ }^{4,5}$ \\ ${ }^{1}$ Atatürk University, Fisheries Faculty, Department of Fundamental Fisheries Sciences, 25240 \\ Erzurum, Turkey, ORCID 0000-0003-4332-522X \\ ${ }^{2}$ Omar Al-Mukhtar University, Veterinary Faculty, Al-Bayda, Libya \\ ${ }^{3}$ High Institutes for Health Professions, Az-Zahra, Libya \\ ${ }^{4}$ Biotechnology Research Center, Authority of Science Research \\ Technology, Tripoli, Libya \\ ${ }^{5}$ Kastamonu University, Engineering and Architecture Faculty, Department of Genetics and \\ Bioengineering, 37200 Kastamonu, Turkey \\ *Corresponding author
}

\section{Keywords}

Medicinal plants,

Macrofungi,

Antimicrobial activity, Essential oil similarity

Article Info

Accepted:

07 October 2019

Available Online:

10 November 2019

\section{A B S T R A C T}

In this study, essential oils obtained with water/steam distillation methods from plants of natural flora of Libya and two macrofungi from natural flora of Turkey were tested antimicrobial activity in vitro for isolated from humans and pathogenic Enterococcus faecium, Escherichia coli, Klebsiella pneumoniae, Proteus vulgaris, Pseudomonas aeroginosa and Staphylococcus aureus bacteria and for isolated from fish and pathogenic Citrobacter freundii, Edwardsiella tarda, Lactococcus garvieae and Yersinia ruckeri bacteria. There were found statistical similarity essential oils but it was not affected antimicrobial activity. However, there are a lot of effected factors for essential oil components such as plantation, texture, and structure of grown soil, climate, the moisture of the air, vegetation time, collection period, collected part of plants...etc. For these reasons, we must apply a machine learning application for the best sample collection time and preferred compounds.

\section{Introduction}

Microorganisms and their metabolic, physiological and genetic differences are the most important factor affecting the health of vertebrate. In addition to normal infectious diseases, the number of infections due to nosocomial and opportunistic pathogens is 
increasing day by day. Also, there is an increase in infections due to diseases caused by drug-resistant pathogens and immunological failure. Side effects such as immune suppression, hypersensitivity and allergic reactions are seen in antibiotic treatments (Chebaibi and Filali, 2013). Besides, antibiotics affect not only target pathogens but also non-target microbial populations in the treatment process. In some cases, antibiotic-induced diarrhea arises as a result of imbalance in the intestinal microbiota (Jernberg et al., 2010). The search for novel antimicrobials of plant origin has gained importance due to the increase of resistance to the drugs in pathogenic microorganisms and the undesirable side effects of some antibiotics (Alviano and Alviano, 2009).

Medical plants include a wide variety of components that can be used in the treatment of chronic diseases as well as infectious diseases. Today, research on developed and developing countries; have concentrated on the medical values of the chemicals in the structures of medicinal and aromatic plants used in the field of traditional medicine, which have definite physiological effect on the human body. The most important of these bioactive compounds in the construction of medical and aromatic plants are alkaloids, flavonoids, tannins and phenolic compounds.

The components of natural products obtained from plants are effective in various ways on microorganisms. The most common mechanism of action of antimicrobial compounds obtained from plants; degradation of cytoplasmic membrane, inhibition of degradation and synthesis of DNA / RNA function, initiation of clotting of cytoplasmic components and inhibition of normal cell communication (Radulovic et al., 2013). Some of the compounds obtained from plants, which are an important source in the treatment of diseases, also called plant derivatives, are derived from essential oils (Mekonnen et al., 2016). Essential oils are aromatic oleaginous liquids obtained from various parts of the plant (flowers, leaves, buds, seeds, weeds, trees, bark, fruits and roots) and the ratio may vary between different parts of the plant. Generally, water/steam distillation method is used when obtaining essential oils (Gültepe 2018).

Essential oils obtained from many medical and aromatic sources; antifungal, antifungal, antiviral, antioxidant, antidiabetic, antiinflammatory, anticancer activity, as well as treatment of many other conditions related to treatment fires, insect bites and skin (Holetz et al., 2002; Prabuseenivasan et al., 2006; Alviano and Alviano, 2009; Kazemi et al., 2012; Mekonnen et al., 2016). Qualitative, quantitative variability and effects of essential oil obtained from plants when assessed individually; the genetic character of the plant depends on its age and on the environment it is growing.

In this study, essential oils obtained with water/steam distillation methods from plants of Artemisia herba alba, Capparis spinosa, Globularia alypum, Matricaria chamomilla, Ocimum basilicum, Origanum majorana, Peganum harmala, Phagnalon rupestre, Punica granatum peel and Thymus vulgaris collected from natural flora of Libya and Lactarius deliciosus and Pleurotus ostreatus collected from natural flora of Turkey were tested antimicrobial activity in vitro for isolated from humans and pathogenic Enterococcus faecium, Escherichia coli, Klebsiella pneumoniae, Proteus vulgaris, Pseudomonas aeruginosa and Staphylococcus aureus bacteria and for isolated from fish and pathogenic Citrobacter freundii, Edwardsiella tarda, Lactococcus garvieae, and Yersinia ruckeri bacteria. The aim of this study is to evaluate the statistical similarity of components of essential oils of these plants 
and macrofungi, and also its effects on antimicrobial activity.

\section{Materials and Methods}

\section{Plants and macrofungi}

More than 100 plant species in Libya are widely used by the Bedouin in medical treatment. These plants collected from four main centers; first area is the El-Jabal ElAkhdar which has about $50 \%$ of the total endemic species, second area is the coastal belt, third area the central part of Sahara and fourth area is southern part of Libya involving Jabal Al Awaynat, Tibesti, and Plateau of Ghat (El-Darier and El-Mogaspi, 2009; Bufrag et al., 2017). Artemisia herba alba, Capparis spinosa, Globularia alypum, Matricaria chamomilla, Ocimum basilicum, Origanum majorana, Peganum harmala, Phagnalon rupestre, Punica granatum peel, and Thymus vulgaris were obtained from a commercial company in Libya.

There are 2422 macrofungi species in Turkey (Solak et al., 2015). Most of them grow naturally in Kastamonu forests in the Black Sea Region and are sold commercially. Lactarius deliciosus and Pleurotus ostreatus were purchased from locally commercial company.

\section{Bacteria}

From human pathogens; Enterococcus faecium, Escherichia coli, Klebsiella pneumoniae, Proteus vulgaris, Pseudomonas aeruginosa and Staphylococcus aureus bacteria used, which were obtained from Gazi University Research and Application Hospital in Ankara-Turkey.

From fish pathogens; Citrobacter freundii (KX388233.1), Edwardsiella tarda (KX388234.1), Lactococcus garvieae
(KY118086.1) and Yersinia ruckeri (KX388238.1) bacteria used, which were isolated from a fish farm in Turkey, sequenced at National Center for Biotechnology Information Laboratory and registered at GenBank.

\section{Experimental procedure}

The essential oil of plants was obtained from dry plants and fresh macrofungi by hydrodistillation, using a Clevenger system with $150 \mathrm{~g}$ dry plant material and $1500 \mathrm{ml}$ water. The oil was obtained after $3 \mathrm{~h}$ of distillation at boiling temperature and stored at $4 \pm 1{ }^{\circ} \mathrm{C}$ in airtight glass vials covered with aluminum foil. The gas chromatography-mass spectrophotometry (GC-MS) analysis of the obtained essential oil was conducted at the Kastamonu University Center Research Laboratory Application and Research Center by using a Shimadzu GCMS QP 2010 ULTRA (Bufrag et al., 2017).

Bacteria were cultured on enriched tryptic soy (TS) agar. Incubation carried out at $37^{\circ} \mathrm{C}$ for $48 \mathrm{~h}$ to human pathogens and $25^{\circ} \mathrm{C}$ for $48 \mathrm{~h}$ to fish pathogens. Individual colonies grown on these re-streaked plates were used in the antimicrobial sensitivity tests. Each pure culture of bacteria was added to sterile phosphate buffer solutions and their concentrations were adjusted with the use of a spectrometer as a $30 \%$ transmittance $(525 \mathrm{~nm})$ according to McFarland 1. In vitro assays were conducted to determine the antimicrobial activity of essential oils. For the essential oil dilutions 250, 500, 1000 and $1250 \mu \mathrm{l}$ in test tubes containing $5 \mathrm{ml}$ phosphate buffer solution was prepared. Aliquots $(0.1 \mathrm{ml})$ of the standardized bacterial isolates were added to each tube and left to stand at room temperature for $1 \mathrm{~h}$, after which a loopful material from each tube was inoculated onto plates. Human pathogens at the $37^{\circ} \mathrm{C}$ for $48 \mathrm{~h}$, fish pathogens at the $25^{\circ} \mathrm{C}$ for $48 \mathrm{~h}$ were 
incubated. Control tubes containing sterile phosphate buffer were each inoculated with aliquots of standardized bacteria and cultured onto plates at the same conditions. At the bacteriological study, Merck (Merck, Germany) media were used (Cipriano et al., 1996; Aydın et al., 2000; Gültepe and Aydın, 2009).

\section{Statistical analysis}

Data were analyzed by one-way analysis of variance (ANOVA), followed by Tukey multiple range test to determine significant differences $(p<0.05)$.

\section{Results and Discussion}

GS-MS, three compounds with the greatest amount were given in Table 1. Methyl stearate was found at both plants and macrofungi essential oils on FAMEs analyses but not found at macrofungi on aroma analyses. Metilox and methyl palmitate were found at both plants and Lactarius deliciosus but not found at Pleurotus ostreatus on FAMEs analyses and also they were not found on aroma analyses of macrofungi. Statistical analyses result of the essential oils of the plants both FAMEs and aroma were given in Figure 1 and 2.

There is extensive use of Artemisia herba alba as an aromatic and medicinal plant in folk medicine and also different studies were made by scientists. Some studies reported that the chemical composition of the essential oil of the A. herba alba was dominated by $\alpha$ - and $\beta$ thujone (Mighri et al., 2009; DahmaniHamzaoui and Baaliouamer, 2015). $\alpha-$ and $\beta$ thujone were not found, but eucalyptol (39.67\%), methyl stearate $(15.17 \%)$ and $1(\mathrm{~S})$ camphor $(6.65 \%)$ were dominated in this research. Similarly, thujone was not found in Spain's population of the A. herba alba (Feuerstein et al., 1988). Furthermore, Eastern
Morocco population of these plants included eucalyptol (Imelouane et al., 2010). Minimum inhibitory concentration (MIC) of the essential oil of Artemisia herba alba has a for Edwardsiella tarda (KX388234.1) at $1000 \mu 1$ dose and for Enterococcus faecium, Escherichia coli, Klebsiella pneumonia, Proteus vulgaris, Pseudomonas aeruginosa and Staphylococcus aureus at $1250 \mu 1$ dose. Morocco population of A.herba alba has a microbial activity for $S$. aureus, $K$. pneumonia, and $E$. coli but not effect $S$. aureus and $P$. aeruginosa (Imelouane et al., 2010). Besides, the Tunisian population of this plant has a positive effect at the $S$. aureus and E. coli (Mighri et al., 2010). Also, an extract of the Libyan population of A. herba alba has an antimicrobial activity for $E$. coli, $P$. aeruginosa, S. aureus (Bogdadi et al., 2007). This result shows that the essential oil of Artemisia herba alba of Libyan population is not suitable for use as antimicrobial at this condition because it should be used in high doses.

Some studies reported (Tlili et al., 2011; Kulisic-Bilusic et al., 2012; Muhaidat et al., 2013)., Capparis species have therapeutic properties with contained compounds. The main component of the $C$. spinosa essential oil is kaempferol derivatives and isopropyl isothiocyanate (Inocencio et al., 2000; Siracusa et al., 2011). In this study, methyl stearate (38.83\%), metilox (14.68\%) and methyl palmitate $(12.40 \%)$ were found as the main components.

Although the effect of caper extracts obtained by different extraction methods on various microorganisms has been reported (Tlili et al., 2011; Muhaidat et al., 2013), C. spinosa essential oil derived from Libyan population has only affected Escherichia coli at $250 \mu 1$ MIC dose as a consequence it can be used as an antimicrobial against E. coli. Globularia species have been medically used for many 
years in both African and European countries (Cero et al., 2014; Jamila and Mostafa, 2014; Ramdani et al., 2014). Chemical composition of the essential oil of the Globularia alypum was dominated by methyl palmitate at the Boutaleb (14.64\%) and Khenchela (29.52\%) populations (Ramdani et al., 2014). Methyl palmitate rate was found $7.23 \%$ and also methyl stearate $(44.61 \%)$, metilox $(17.15 \%)$ and tetradecane $(11.39 \%)$ were dominated in this research.

Origanum majorana is known for its medicinal properties and usage in the food industry. The essential oil of the Venezuelan Andes population of $O$. majorana was contained cis-sabinene hydrate $(30.2 \%)$, terpinen-4-ol (28.8\%), $\gamma$-terpinene $(7.2 \%), \alpha$ terpineol (6.9\%), trans-sabinene hydrate (4.4\%), linalyl acetate (3.8\%) and $\alpha$-terpinene (3.6\%) (Ramos et al., 2011). Similarly, oil of the Tunisian population of $O$. majorana was dominated by terpinen-4-ol (32.8\%), $\gamma$ terpinene $(9.9 \%)$, cis-sabinene hydrate $(8.6 \%)$, and $\alpha$-terpineol (5.6\%) (Ezzeddine et al., 2001). In this study, essential oil of the Libyan population of $O$. majorana was dominated by $\gamma$-terpinene $(17.61 \%)$, methyl stearate (16.04\%) and $\alpha$-terpineol (5.6\%).

At the end of the twentieth century, a lot of studies were conducted about the different part of pomegranate (Punica granatum) related to essential oil components, antioxidant and antimicrobial effects. Camphor (60.32\%), benzaldehyde (20.98\%) and (4)-borneol $(4.75 \%)$ were dominated essential oil of the Tunisian population of pomegranate peel (Hadrich et al., 2014). Methyl stearate (43.21\%), metilox (16.82\%) and methyl palmitate $(7.90 \%)$ were dominated essential oil of the Libyan population of pomegranate peel in this research.

Globularia alypum essential oil has significant inhibitory action on Acinetobacter baumanii,
Citrobacter freundii, Escherichia coli, Salmonella typhimurium, Bacillus subtilus, Enterococcus faecalis, Listeria monocytogenes, but has not got effect on Klebsiella pneumoniae, Proteus mirabilis, Staphylococcus aureus, Pseudomonas aeruginosa, Bacillus cereus (Ramdani et al., 2014), and also Boussoualim et al., (2014), reported that methanolic extract of the Globularia alypum inhibits Pseudomonas aeruginosa, Escherichia coli, Salmonella typhimurium, Acinetobacter baumanii, Citrobacter freundii, Proteus mirabilis, Klebsiella pneumoniae, Staphylococcus aureus, Bacillus cereus, and Enterococcus faecalis. The essential oil of the Origanum majorana has an inhibitory effect to Escherichia coli, Klebsiella pneumoniae, and Salmonella enteritidis but no any effect for Pseudomonas aeruginosa, Staphylococcus aureus, Streptococcus A, Enterococcus faecalis, Proteus mirabilis, Shigella dysenteria and Staphylococcus epidermitis by agar diffusion method (Ezzeddine et al., 2001). Extracts of different parts of $P$. granatum have an inhibitory effect to methicillin-sensitive Staphylococcus aureus, methicillin-resistant Staphylococcus aureus, Micrococcus luteus, Enterobacter aerogenes, Pseudomonas aeruginosa, Escherichia coli, Salmonella typhi, Salmonella enteric and some streptococci strains (Prakash and Prakash, 2011; Kaur et al., 2016). This study result show that $1250 \mu \mathrm{l}$ dose of essential oils of Globularia alypum, Origanum majorana, and Punica granatum peel has a weak antimicrobial activity for Enterococcus faecium, Escherichia coli, Klebsiella pneumonia, Proteus vulgaris, Pseudomonas aeruginosa, and Staphylococcus aureus.

Studies with the essential oil of Ocimum basilicum are given different results to us for example: Iranian population methyl chavicol $(47.0 \%)$, geranial $(19.0 \%)$ and neural $(15.0 \%)$ (Kavoosi and Amirghofran, 2017); different 
varieties $(O$. basilicum var. purpurascens and $O$. basilicum var. dianatnejadii) of another Iranian population methyl chavicol $(43.0 \%$ and $37.6 \%)$, linalool $(28.9 \%$ and $33.4 \%), \alpha-$ Cadinol (1.0\% and 5.7\%) and $\alpha$-Eudesmol (4.7\% and $0.9 \%$ ) respectively (Dolatabad et al., 2014); different varieties (Ocimum basilicum var. basilicum, Ocimum basilicum var. difforme and Ocimum basilicum var. purpurascens) of Croatia population linalool $(66.40 \%, 20.82 \%$ and $0 \%)$, eugenol $(8.26 \%$, $0 \%$ and $0.43 \%), \alpha$-bergamotene $(7.96 \%$, $6.84 \%$ and $0 \%)$, estragole $(0 \%, 47.52 \%$ and $94.57 \%)$, methyl eugenol $(0.31 \%, 0.13 \%$ and $1.23 \%), 1,8$-cineole $(7.23 \%, 6.17 \%$ and $0 \%)$ and -bisabolene (0\%, $0 \%$ and $1.12 \%)$ respectively (Carović-Stanko et al., 2013). Essential oil of the Libyan population of $O$. basilicum was dominated by methyl stearate (29.16\%), metilox (10.57\%) and docosane $(9.87 \%)$ in this study.

Although there are a lot of studies on the presence of n-paraffins, fatty substances, terpenoids, flavonoids, glycosides of $P$. rupestre (Senatore et al., 2005), there is no find study with the chemical composition of essential oil of the $P$. rupestre. According to study results, $P$. rupestre essential oil was dominated by methyl stearate $(53.83 \%)$, metilox (16.84\%) and methyl palmitate $(9.35 \%)$.

There were a lot of studies with the antimicrobial and antifungal activity of $O$. basilicum essential oil. Data on the antibacterial activity of $O$. basilicum were higher than data on antifungal activity (Suppakul et al., 2003). Suppakul et al., (2003) based on different studies reported that it was more effective against Gram-positive than against Gram-negative bacteria, and also has potential use in food preservation.

Extract of the Phagnalon rupestre has antimicrobial activity against Staphylococcus aureus, Escherichia coli, Klebsiella pneumoniae, Proteus vulgaris, Pseudomonas aeruginosa and Candida albicans (AliShtayeh et al., 1998), and also a positive effect for contact hypersensitivity (Olmos et al., 2007; Giner et al., 2011). This study results showed Ocimum basilicum and Phagnalon rupestre essential oils MIC value at $1000 \mu \mathrm{l}$ dose for Edwardsiella tarda and also they have weak antimicrobial activity at $1250 \mu \mathrm{l}$ dose for Enterococcus faecium, Escherichia coli, Klebsiella pneumonia, Proteus vulgaris, Pseudomonas aeruginosa, and Staphylococcus aureus.

Matricaria chamomilla is a historical plant as a medicinal usage. Currently, it is cultivated due to different specialization such as medicinal, aromatic and flavoring properties. Essential oil of the Turkish population of Matricaria chamomilla was dominated by bisabolone oxide (47.6\%), bisabolol oxide A (27.4\%), en-yn-dicycloether (5.6\%) and bisabolol oxide A (75.4\%), followed by en-yndicycloether (4.4\%) and bisabolol oxide B (4.1\%) at 2011 and 2012, respectively (Rezaeih et al., 2015). Bosnia and Herzegovina population of its was dominated by $(\mathrm{E})-\beta$-farnesene $(29.8 \%),(\mathrm{E}, \mathrm{E})-\alpha$-farnesene $(9.3 \%)$ and $\alpha$-bisabolol oxide A $(7.0 \%)$ (Stanojevic et al., 2016) and also Ethiopian population was dominated by $\alpha$-bisabolol oxide B (51.428\%), chamazulene/azulene $(17.688 \%)$ and en-in-dicycloether $(10.841 \%)$ (Mekonnen et al., 2016). The essential oil of the Libyan population of $M$. chamomilla was dominated by methyl stearate $(26.02 \%)$, metilox (10.17\%) and undecane $(9.18 \%)$ in this study.

Interestingly, essential oil of M. chamomilla was not shown antimicrobial activity against Staphylococcus aureus, Staphylococcus epidermidis, Pseudomonas aeruginosa, Shigella flexneri, Klebsiella pneumoniae, Salmonella typhi, Serratia marcescens, and 
Escherichia coli for Ethiopian population (Mekonnen et al., 2016). Bosnia and Herzegovina's population of its give similar results against Pseudomonas aeruginosa, in spite of, it has antimicrobial activity Listeria monocytogenes, Escherichia coli, Salmonella enterica and Staphylococcus aureus (Stanojevic et al., 2016). Study results show that essential oil of Matricaria chamomilla has weak antimicrobial activity against Edwardsiella tarda, Enterococcus faecium, Escherichia coli, Klebsiella pneumonia, Proteus vulgaris, Pseudomonas aeruginosa and Staphylococcus aureus at $1250 \mu \mathrm{l}$ dose.

Peganum harmala, which treats asthma, hiccough, colic, neuralgia, hysteria, and dysmenorrhea, is widely used owing to its medicinal properties in the Middle East and Asia countries (Sînâ 1998). Researchers were found different results related to the essential oil components of $P$. harmala populations. While Iranian population dominated by $\alpha$ pinene $(72.6 \%)$, trans-verbenole (3.9\%) and sabinene (2.6\%) (Faridi et al., 2013), Pakistan population was dominated by alcanfor (28.24\%), capillin $(13.176 \%)$ and eugenyl methyl (9.674\%) (Dastagir et al., 2014).

Another study reported that, eugenol (17.5\%), thymol (7.0\%) and $\alpha$-isomethyl-(E)-ionol (7.0\%); eugenol (17.2\%), n-tetradecanol $(12.3 \%)$ and dodecanoic acid (5.9\%); eugenol (17.8\%), n-tetradecanol (11.3\%) and $\beta$ acorenolo (7.4\%); eugenol (13.2\%), ntetradecanol $(11.1 \%)$ and bakerol $(7.5 \%)$; and eugenol $(69.2 \%)$, eugenol acetate $(9.0 \%)$ and (E)-anethol (6.9\%) were dominated to essential oil of the Algeria, Egypt, Libya, Morocco and Tunisia populations, respectively (Apostolico et al., 2016). In this study, results differ from all of them, in such a way that, it was dominated by methyl stearate (29.33\%), eicosane (11.31\%) and metilox
(7.06\%). Apostolico et al., (2016) reported that all samples were capable of inhibiting the growth of the B. cereus strains, E. coli, $P$. aeruginosa and $S$. aureus but they cannot explain different antimicrobial activity with the chemical composition of the essential oils.

MIC values of the Peganum harmala essential oil at $250 \mu \mathrm{l}$ were found against to Lactococcus garvieae but no any antimicrobial activity to other test bacteria.

For many years, Thymus vulgaris has been extensively used for expectorant, antitussive, antispasmodic, antibroncholitic, carminative, diuretic and anthelmintic properties as a folkloric. T. vulgaris essential oils, which are collected from seven different areas at Italy and France, were rich in thymol (from $22.11 \%$ to $38.45 \%$ ) accompanied by its biogenetic precursors $\rho$-cymene (from $21.5 \%$ to $44.9 \%$ ) and $\gamma$-terpinene (from $0 \%$ to $17.3 \%$ ) (Zambonelli et al., 2004). Besides, essential oil of $T$. vulgaris from collected six different areas of Albania were dominated by thymol (from $32.02 \%$ to $53.29 \%$ ), $\rho$-cymene (from $14.76 \%$ to $20.07 \%$ ) and $\gamma$-terpinene (from 9.53\% to $13.18 \%$ ) (Asllani and Toska, 2003). Also, the Campania Region in Southern Italy population of $T$. vulgaris essential oil was dominated by thymol $(33.02 \pm 0.3 \%), \rho-$ cymene $(24.3 \pm 0.3 \%)$ and carvacrol $(8.6 \pm 0.1 \%)$ (Catauro et al., 2017).

Camphor (38.54\%), camphene $(17.19 \%)$ and $\alpha$-pinene $(9.35 \%)$ were obtained from the essential oil of $T$. vulgaris Morocco population (Imelouane et al., 2009). Similar to some Italy and France population, $\rho$-cymene $(54.23 \%)$ was highly percentage of the essential oil composition. However, methyl stearate $(23.26 \%)$ and $\gamma$-terpinene $(4.90 \%)$ were dominated by $T$. vulgaris essential oil in this study. 
Table.1 Quantity and structure of the first three compounds of essential oils

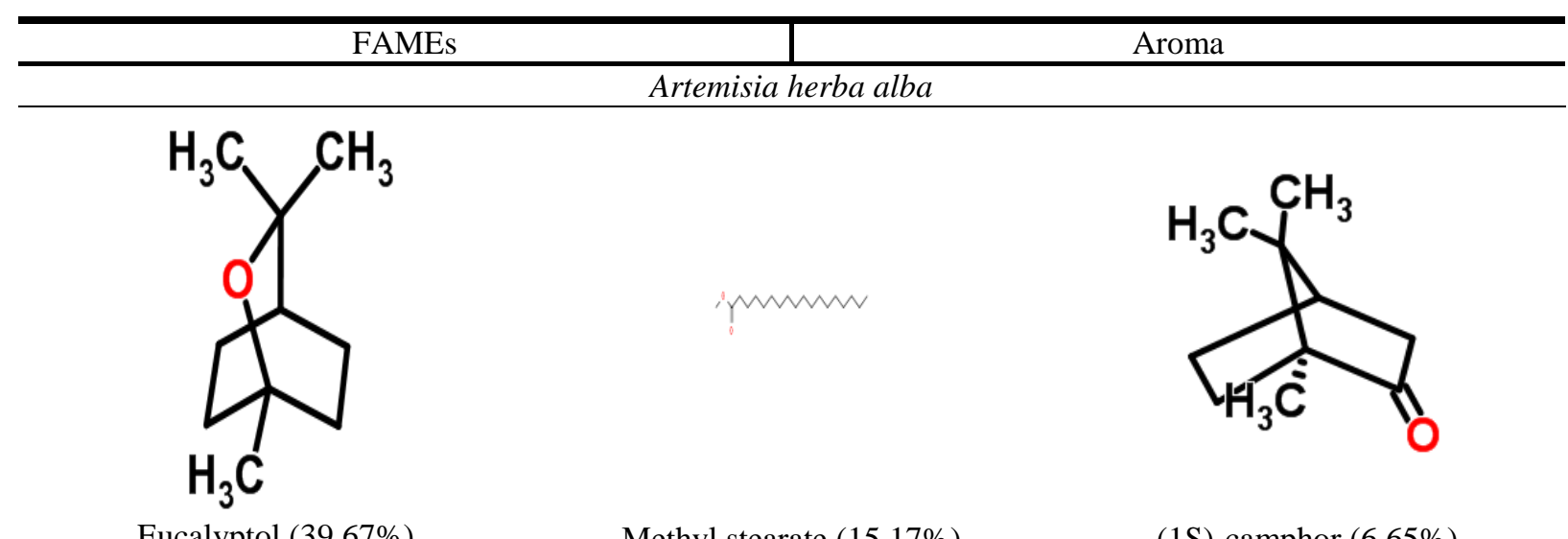

Methyl stearate (38.83\%) Capparis spinosa


Table.1 Quantity and structure of the first three compounds of essential oils (continued)

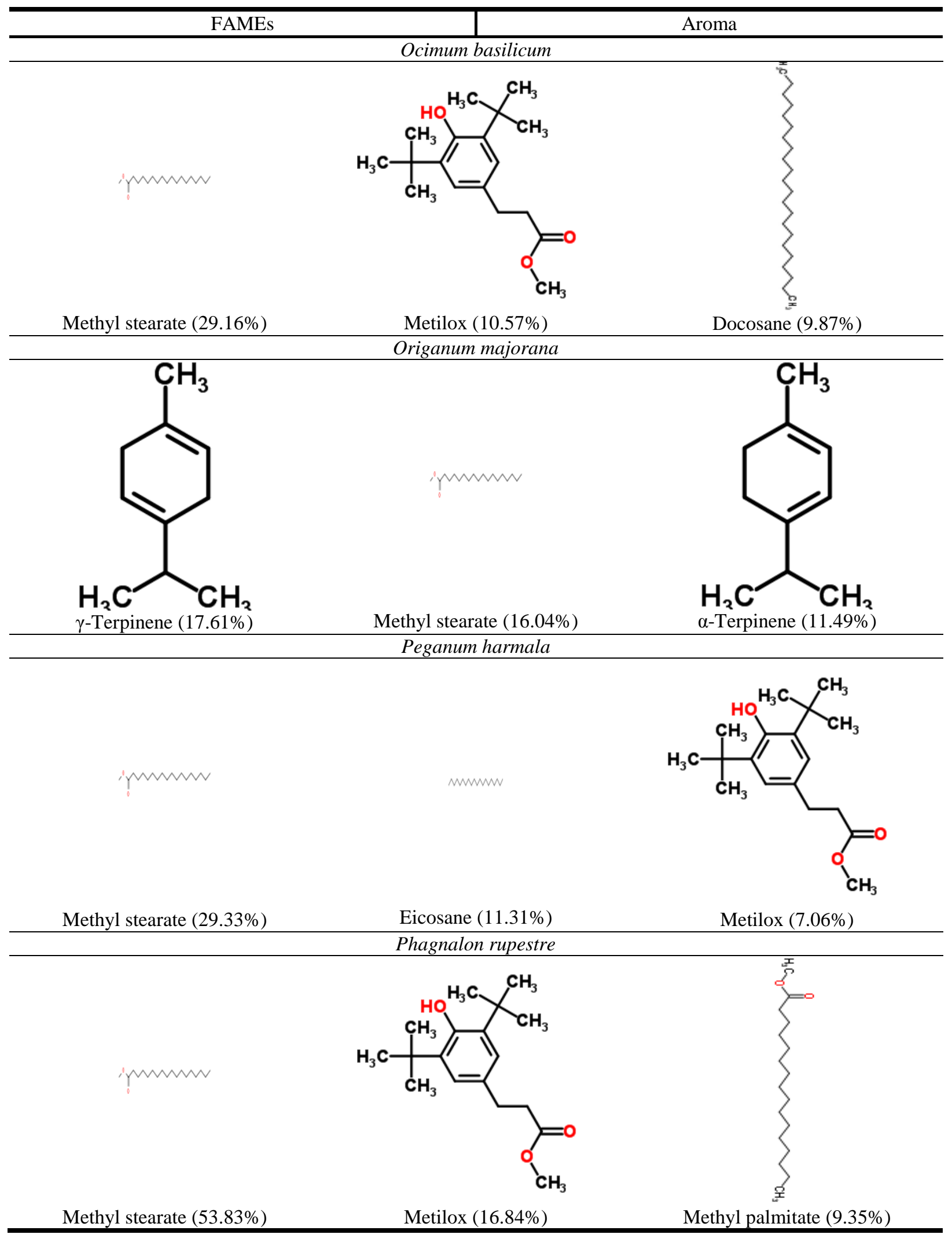


Table.1 Quantity and structure of the first three compounds of essential oils (continued)

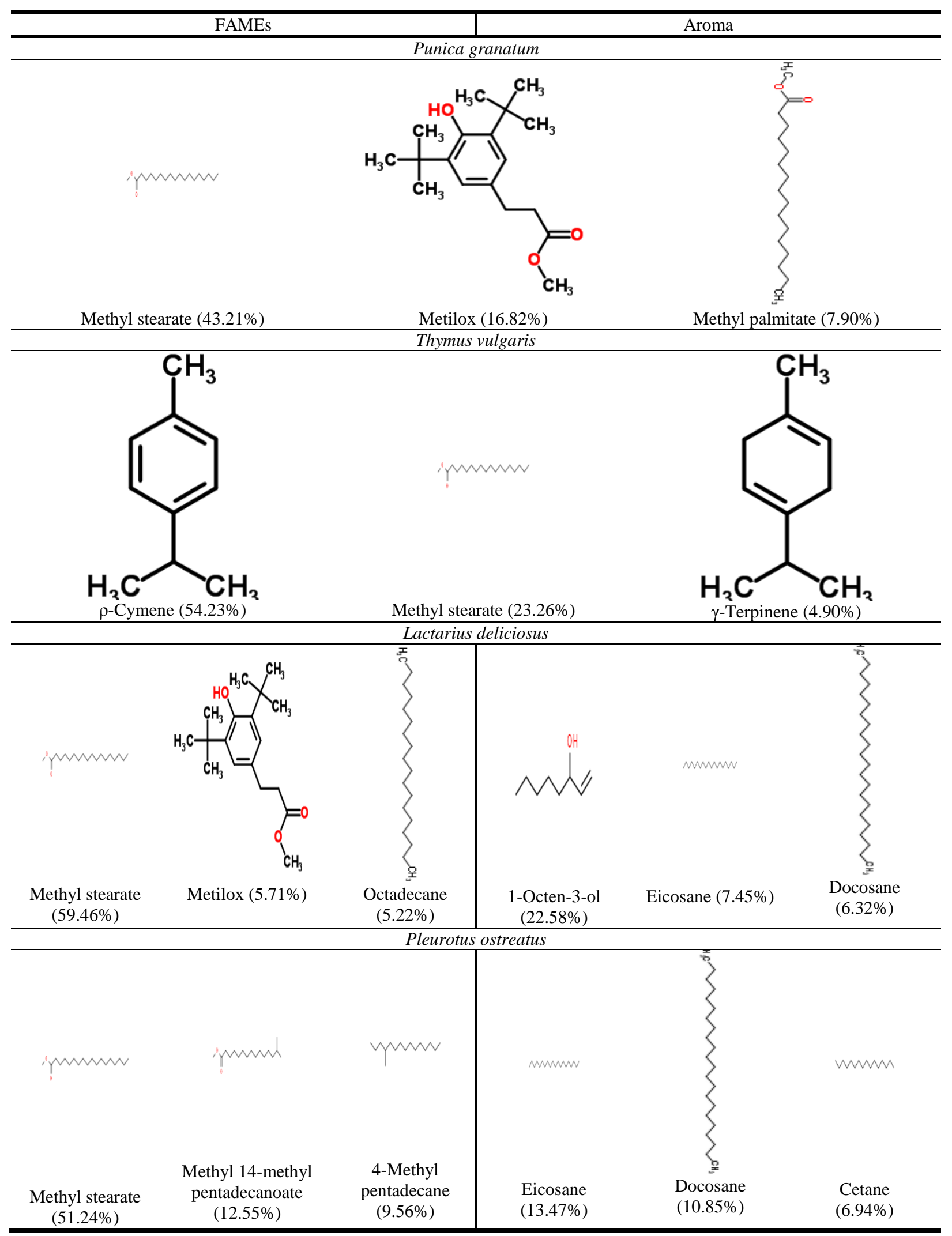


Fig.1 The statistical similarity of the FAMEs analyses results of essential oils

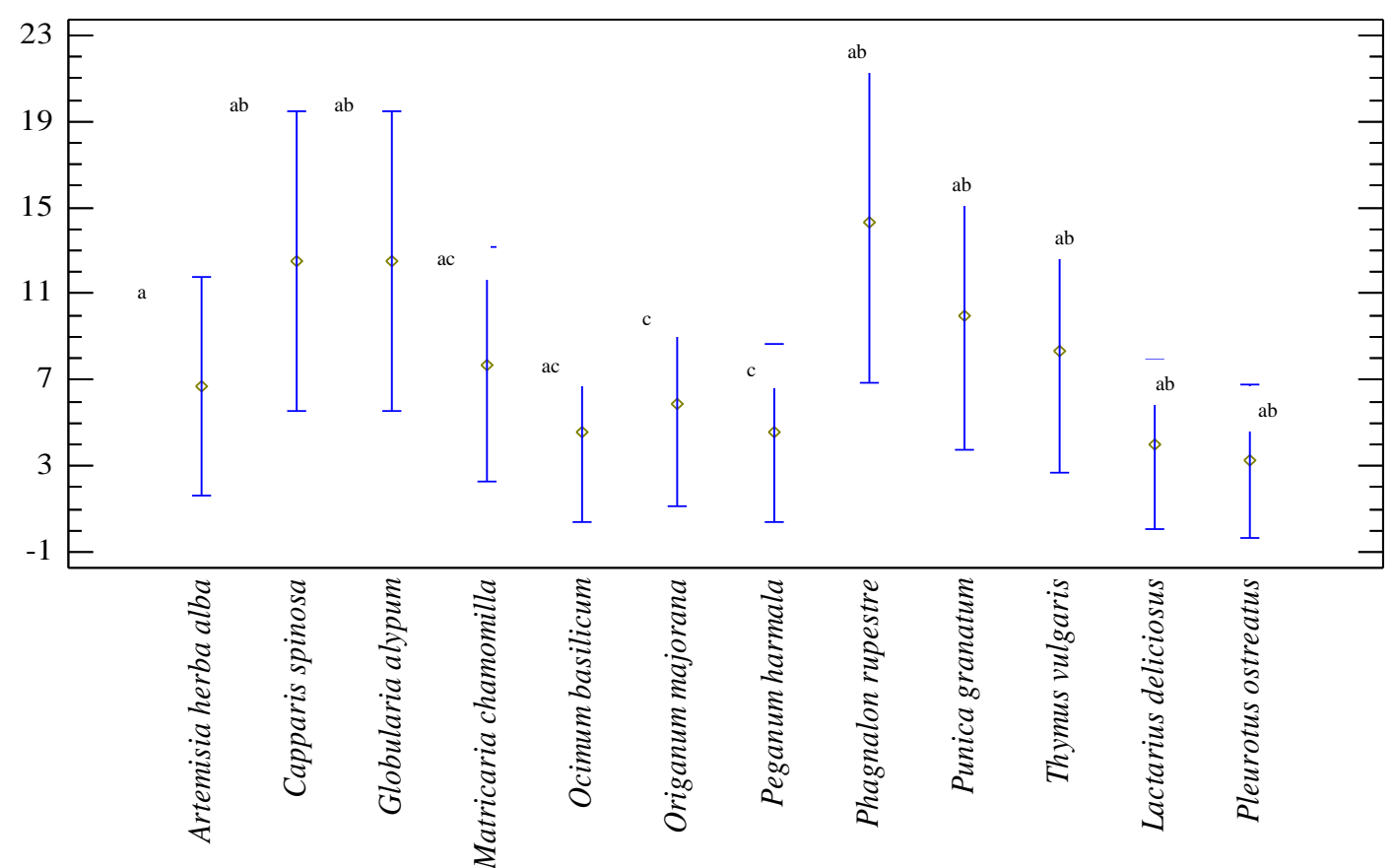

Within the graph, means with different superscripts are significantly different $(\mathrm{P}<0.05)$.

Fig.2 The statistical similarity of the aroma analyses results of essential oils

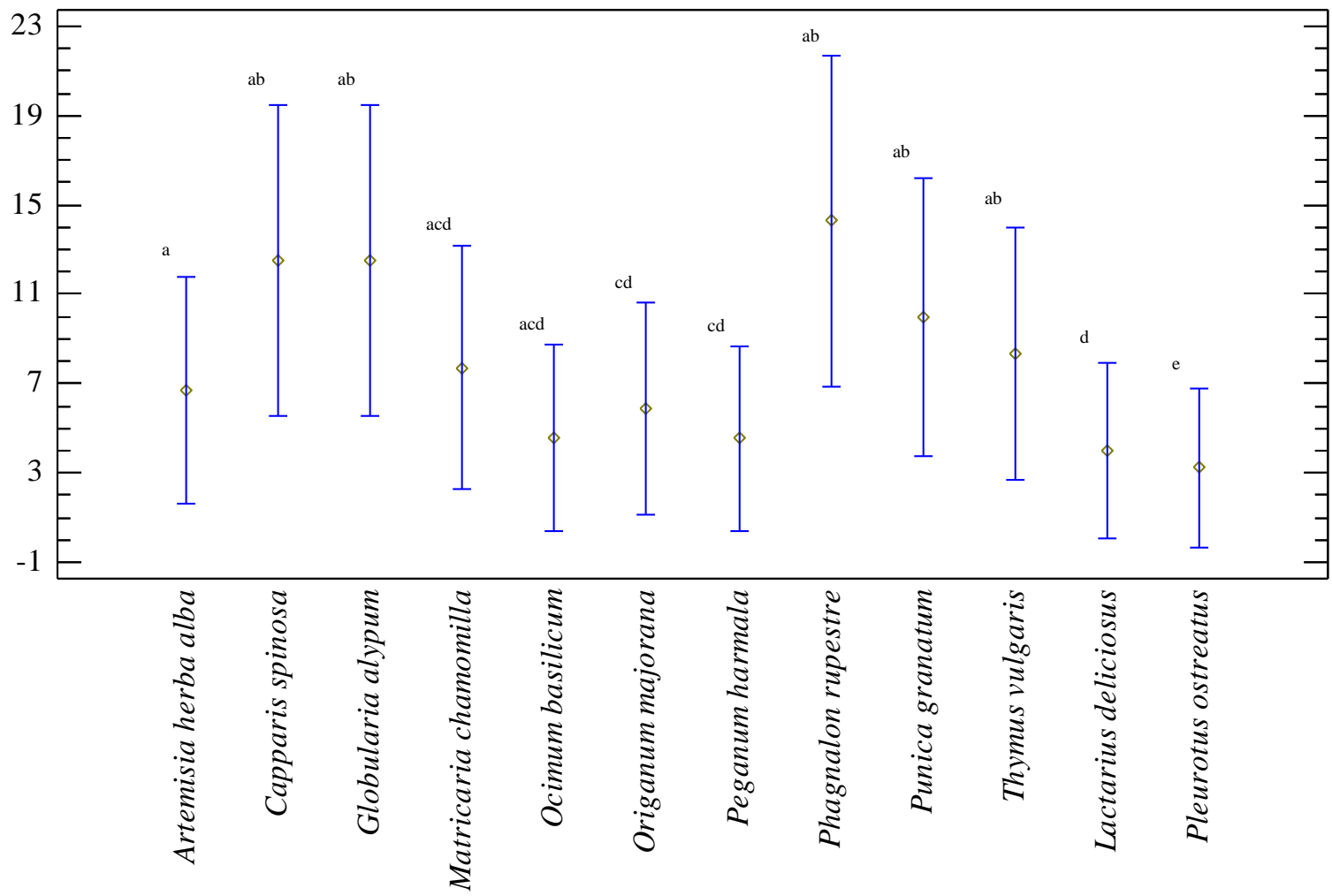

Within the graph, means with different superscripts are significantly different $(\mathrm{P}<0.05)$. 
T. vulgaris essential oil has fungicidal activity against Fusarium solani, Rhizoctonia solani and Colletotrichum lindemuthianum and also the fungicidal activity of the oils was correlated with their thymol content (Zambonelli et al., 2004). MIC values of essential oil of $T$. vulgaris Morocco population were found $0.66 \mathrm{mg} / \mathrm{ml}$ for Pantoa sp.; $1.33 \mathrm{mg} / \mathrm{ml}$ for $S$. aureus, S. epidermidis and E. coli; and $2.67 \mathrm{mg} / \mathrm{ml}$ for Streptococcus sp. (Imelouane et al., 2009). MIC values of Thymus vulgaris essential oil was found 250 $\mu \mathrm{l}$ for Edwardsiella tarda, $1000 \mu \mathrm{l}$ for Lactococcus garvieae and also $1250 \mu \mathrm{l}$ dose for Enterococcus faecium, Escherichia coli, Klebsiella pneumonia, Proteus vulgaris, Pseudomonas aeruginosa and Staphylococcus aureus in this study.

In addition to the use of macrofungi as nutrients, researchers deal with its some compounds to select fragrant components and enter the bioconversion process. Researchers were generally working with extract of Lactarius deliciosus. Its methanolic extract dominated by $o$-coumaric $(497.45 \mathrm{mg} / \mathrm{kg})$, quercetin $(450.87 \mathrm{mg} / \mathrm{kg}$ ) and syringic $(78.64$ $\mathrm{mg} / \mathrm{kg}$ ) (Dundar et al., 2016). There is no find study with the chemical composition of essential oil of the $L$. deliciosus. The essential oil of Pleurotus ostreatus was dominated by octen-3-ol (59.3), 3-octanol (5.8\%) and octan3-one (5.3\%) (Nyegue et al., 2003). FAMEs and aroma analyses of the essential oil of both $L$. deliciosus and P. ostreatus were found differently from each other. Methyl stearate (59.46\%), Metilox (5.71\%), methyl palmitate $(5.15 \%)$ and 1-octen-3-ol (22.58\%), eicosane (7.45\%), docosane $(6.32 \%)$ were dominated essential oil of $L$. deliciosus at the FAMEs and aroma analyses. FAMEs result shows that methyl stearate (51.24\%), methyl 14-methyl pentadecanoate $(12.55 \%)$ and 4-methyl pentadecane $(9.56 \%)$ dominated Pleurotus ostreatus essential oil. According to aroma results, eicosane $(13.47 \%)$, docosane $(10.85 \%)$ and Cetane (6.94\%) were dominated it.
The methanol extract of $L$. deliciosus has antimicrobial activity against $S$. aureus, $E$. coli, Enterococcus hirae and $P$. aeruginosa but no antimicrobial activity against Micrococcus luteus and Bacillus subtilis (Nyegue et al., 2003). Extract of L. deliciosus, which is extracted with solvent cocktail (distilled water (1), ethanol (2.5), methanol (2.5), acetone (2), methylene chloride (2)), has an antimicrobial activity against $P$. aeruginosa and Shigella flexneri but has not got antimicrobial activity against Escherichia coli, Salmonella enterica and Candida albicans (Altuner and Akata, 2010). The liquid filtrate of $P$. ostreatus has inhibitory activity $P$. aeruginosa, E. faecalis, C. parapsilosis but not show inhibition against $E$. coli and $S$. aureus (Owaid et al., 2015). The crude extract of $P$. ostreatus has an inhibition C. albicans, $P$. aeruginosa and $S$. aureus but no inhibitory effects for E. faecalis, E. coli and Klebsiella pneumonia (Bawadekji et al., 2017). In this research, essential oils of the L. deliciosus and $P$. ostreatus have not any antimicrobial effects for these bacteria.

Also, the essential oils of these plants did not show any antimicrobial activity against Citrobacter freundii and Yersinia ruckeri bacteria.

In conclusion, there were find similarity between essential oils components of both these plants and macrofungi, it was not affected antimicrobial activity against researched bacteria. Essential oils of plants may have been included similar compounds but this condition is insufficient for similar antimicrobial activity. However, there are a lot of affected factors for essential oil components such as plantation, texture, and structure of grown soil, climate, the moisture of the air, vegetation time, collection period, collected part of plants...etc. For these reasons, it will not be appropriate to use essential oils alone. To eliminate this condition, we must apply a 
machine learning application for best sample collection time and preferred compounds.

\section{References}

Ali-Shtayeh MS, Yaghmour RM-R, Faidi YR, Salem K, Al-Nuri MA (1998). Antimicrobial activity of 20 plants used in folkloric medicine in the Palestinian area. Ethnopharmacology 60: 265-271.

Altuner EM, Akata I (2010). Antimicrobial activity of some macrofungi extracts. Sakarya University Journal of Sciences 14(1): 45-49.

Alviano DS, Alviano CS (2009). Plant extracts: search for new alternatives to treat microbial diseases. Current Pharmaceutical Biotechnology 10(1): 106-121.

Apostolico I, Aliberti L, Caputo L, Feo VD, Fratianni F, Nazzaro F, Souza LF, Khadhr M (2016). Chemical composition, antibacterial and phytotoxic activities of Peganum harmala seed essential oils from five different localities in Northern Africa. Molecules 21: 1235, doi: 10.3390/ molecules21091235.

Asllani U, Toska V (2003). Chemical composition of Albanian thyme oil (Thymus vulgaris L.). Journal of Essential Oil Research 15(3): 165-167.

Aydın S, Gültepe N, Yıldız H (2000). Natural and experimental infections of Campylobacter cryaerophila in rainbow trout: Gross pathology, bacteriology, clinical pathology. Fish Pathology 35(3): 117-123.

Bawadekji A, Mridha MAU, Ali MA, Basha WJ (2017). Antimicrobial activities of oyster mushroom Pleurotus ostreatus (Jacq. ex. Fr.) Kummer. Journal of Applied Environmental and Biological Sciences 7(10): 227-231.

Bogdadi HAA, Kokoska L, Havlik J, Kloucek P, Rada V, Vorisek K (2007). In vitro antimicrobial activity of some Libyan medicinal plant extracts. Pharmaceutical Biology 45(5): 386-391.
Boussoualim N, Trabsa H, Krache I, Arrar L, Khennouf S, Baghiani A (2014). Antibacterial and $\beta$-Lactamase inhibitory effects of Anchusa azurea and Globularia alypum extracts. Research Journal of Pharmaceutical, Biological and Chemical Sciences 5(1): 742-749.

Bufrag SMI, Abughadyra IRA, Gültepe N (2017). Essential oil compounds of some medicinal-aromatic plants grown in Libya. 1st International Congress on Medicinal and Aromatic Plants, TABKON 2017; Konya, Turkey.

Carović-Stanko K, Fruk G, Satovic Z, Ivić D, Politeo O, Sever Z, Grdiša M, Strikić F, Jemrić T (2013). Effects of Ocimum spp. essential oil on Monilinia laxa in vitro. Journal of Essential Oil Research 25(2): 143-148.

Catauro M, Bollino F, Tranquillo E, Sapio L, Illiano M, Caiafa I, Naviglio S (2017). Chemical analysis and anti-proliferative activity of Campania Thymus vulgaris essential oil. Journal of Essential Oil Research 29(6): 461-470.

Cero MD, Saller R, Weckerle CS (2014). The use of the local flora in Switzerland: A comparison of past and recent medicinal plant knowledge. Ethnopharmacology 151(1): 253-264.

Chebaibi A, Filali FR (2013). Bactericidal activity and phytochemical screening of Moroccan pomegranate (Punica granatum Linn.) peel aqueous extracts. Journal of Medicinal Plants Research 7(14): 887-891.

Cipriano RC, Ford LA, Starliper CE, Teska JD, Nelson JT, Jensen BN (1996). Control of external Aeromonas salmonicida: Tropical disinfection of salmonids with Chloramine-T. Journal of Aquatic Animal Health 8: 52-57.

Dahmani-Hamzaoui N, Baaliouamer A (2015). Volatile constituents of Algerian Artemisia herba-alba essential oils. Journal of Essential Oil Research 27(5): 437-446.

Dastagir G, Hussain F, and Rehman IU (2014). Essential oil composition of some plants 
of family Zygophyllaceae and Euphorbiaceae. Pakistan Journal of Botany 46(6): 2043-2049.

Dolatabad SS, Moghaddam M, Chalajour H (2014). Essential oil composition of four Ocimum species and varieties growing in Iran. Journal of Essential Oil Research 26(4): 315-321.

Dundar A, Okumus V, Ozdemir S, Celik KS, Boğa M, Ozcagli E (2016). Determination of cytotoxic, anticholinesterase, antioxidant and antimicrobial activities of some wild mushroom species. Cogent Food \& Agriculture $\quad 2: \quad 1178060$ dx.doi.org/10.1080/ 23311932.2016.1178060.

El-Darier SM, El-Mogaspi FM (2009). Ethnobotany and relative importance of some endemic plant species at El-Jabal El-Akhdar Region (Libya). W J Agri Sci 5(3): 353-360.

Ezzeddine NBH-B, Abdelkéfi MM, Aissa, RB, Chaabouni MM (2001). Antibacterial screening of Origanum majorana L. oil from Tunisia. Journal of Essential Oil Research 13(4): 295-297.

Faridi P, Ghasemi Y, Mohagheghzadeh A (2013). Chemical composition of Peganum harmala smoke and volatile oil. Journal of Essential Oil Bearing Plants 16(4): 469-473.

Feuerstein I, Danin A, Segal R (1988). Constitution of the essential oil from an Artemisia herba-alba population of Spain. Phytochemistry 27(2): 433-434.

Giner E, Alami ME, Máñez S, Recio MC, Ríos J-L, Giner RM (2011). Phenolic substances from Phagnalon rupestre protect against 2,4,6trinitrochlorobenzene-induced contact hypersensitivity. Journal of Natural Products 74: 1079-1084.

Gültepe N (2018). How the use of orange (Citrus sinensis) peel essential oil affected the growth performance of rainbow trout (Oncorhynchus mykiss)? Bulletin of University of Agricultural
Sciences and Veterinary Medicine ClujNapoca. Agriculture 75(1): 16-20.

Gültepe N, Aydın S (2009). Pseudomonas elongata infection in scattered mirror carp: Bacteriology, gross pathology and treatment. Journal of Animal and Veterinary Advances 8(5): 835-838.

Hadrich F, Cherif S, Gargouri YT, Adel S (2014). Antioxidant and lipase inhibitory activities and essential acid composition of pomegranate peel extracts. Journal of Oleo Science 63(5): 515-525.

Holetz FB, Pessini GL, Sanches NR, Cortez DAG, Nakamura CV, Filho BPD (2002). Screening of some plants used in the Brazilian folk medicine for the treatment of infectious diseases. Memorias do Instituto Oswaldo Cruz 97(7): 10271031.

Imelouane B, Amhamdi H, Wathelet JP, Ankit M, Khedid K, Bachiri AE (2009). Chemical composition and antimicrobial activity of essential oil of thyme (Thymus vulgaris) from Eastern Morocco. International Journal of Agriculture and Biology 11(2): 205-208.

Imelouane B, El-Bachiri A, Ankit M, Khedid K, Wathelet JP, Amhamdi H (2010). Essential oil composition and antimicrobial activity of Artemisia herba-alba Asso grown in Morocco. Banat's Journal of Biotechnology 1(2): 48-55.

Inocencio C, Rivera D, Alcaraz F, TomásBarberán FA (2000). Flavonoid content of commercial capers (Capparis spinosa, $C$. sicula and $C$. orientalis) produced in Mediterranean countries. European Food Research and Technology 212(1): 70-74.

Jamila F, Mostafa E (2014). Ethnobotanical survey of medicinal plants used by people in Oriental Morocco to manage various ailments. Ethnopharmacology 154(1): 76-87.

Jernberg C, Löfmark S, Edlund C, Jansson JK (2010). Long-term impacts of antibiotic exposure on the human intestinal microbiota. Microbiology 156(1): 32163223. 
Kaur P, Thakur R, Chaudhury A (2016). Biogenesis of copper nanoparticles using peel extract of Punica granatum and their antimicrobial activity against opportunistic pathogens. Green Chemistry Letters and Reviews 9(1): 3338.

Kavoosi G, Amirghofran Z (2017). Chemical composition, radical scavenging and anti-oxidant capacity of Ocimum basilicum essential oil. Journal of Essential Oil Research 29(2): 189-199.

Kazemi M, Mousavi E, Bandrez N (2012). Chemical compositions and antibacterial activity of the essential oils of Thymus vulgaris and Tanacetum parthenium. Research Journal of Soil Biology 4(2): 21-31.

Kulisic-Bilusic T, Schmöller I, Schnäbele K, Siracusa L, Ruberto G (2012). The anticarcinogenic potential of essential oil and aqueous infusion from caper (Capparis spinosa L.). Food Chemistry 132: 261-267.

Mekonnen A, Yitayew B, Tesema A, Taddese S (2016). In vitro antimicrobial activity of essential oil of Thymus schimperi, Matricaria chamomilla, Eucalyptus globulus, and Rosmarinus officinalis. International Journal of Microbiologyogy doi: 10.1155/2016/9545693.

Mekonnen A, Yitayew B, Tesema A, Taddese S (2016). In vitro antimicrobial activity of essential oil of Thymus schimperi, Matricaria chamomilla, Eucalyptus globulus, and Rosmarinus officinalis. International Journal of Microbiologyogy Article ID 9545693, 8 $\mathrm{p}$, http://dx.doi.org/10.1155/2016/9545693.

Mighri H, Akrout A, Neffati M, Tomi F, Casanova J (2009). The essential oil from Artemisia herba-alba Asso cultivated in Arid Land (South Tunisia). Journal of Essential Oil Research 21(5): 453-456.

Mighri H, Hajlaoui H, Akrout A, Najjaa H, Neffati M (2010). Antimicrobial and antioxidant activities of Artemisia herba-alba essential oil cultivated in Tunisian arid zone. Comptes Rendus Chimie 13: 380-386.

Muhaidat R, Al-Qudah MA, Al-Shayeb A, Jacob JH, Al-Jaber HI, Hussein E, AlTarawneh, IN, Orabi STA (2013). Chemical profile and antibacterial activity of crude fractions and essential oils of Capparis ovata Desf. and Capparis spinosa L. (Capparaceae). International Journal of Integrative Biology 14(1): 39-47.

Nyegue M, Zollo PHA, Bessière JM, Rapior S (2003). Volatile components of fresh Pleurotus ostreatus and Termitomyces shimperi from Cameroon. Journal of Essential Oil Bearing Plants 6(3): 153160.

Olmos A, Giner RM, Recio MC, Rios JL, Cerdá-Nicolás JM, Máñez S (2007). Effects of plant alkylphenols on cytokine production, tyrosine nitration and inflammatory damage in the efferent phase of contact hypersensitivity. British Journal of Pharmacology 152: 366-373.

Owaid MN, Al-Saeedi SSS, Al-Assaffii IAA (2015). Antimicrobial activity of mycelia of oyster mushroom species (Pleurotus spp.) and their liquid filtrates (In vitro). Journal of Medical and Bioengineering 4(5): 376-380.

Prabuseenivasan S, Jayakumar M, Ignacimuthu S (2006). In vitro antibacterial activity of some plant essential oils. BMC Complementary and Alternative Medicine doi: 10.1186/1472-6882-6-39.

Prakash CVS, Prakash I (2011). Bioactive chemical constituents from pomegranate (Punica granatum) juice, seed and peela review. International Journal of Research in Chemistry and Environment 1(1): 1-18.

Radulovic NS, Blagojevic PD, Stojanovic-Radic ZZ, Stojanovic MM (2013). Antimicrobial plant metabolites: structural diversity and mechanism of action. Current Medicinal Chemistry 20(7): 932-952. 
Ramdani M, Lograda T, Ounoughi A, Chalard P, Figueredo G, Laidoudi H, ElKolli M (2014). Chemical composition, antimicrobial activity and chromosome number of Globularia alipum from Algeria. International Journal of Current Microbiology and Applied Sciences 3(7): 306-318.

Ramos S, Rojas LB, Lucena ME, Meccia G, Usubillaga A (2011). Chemical composition and antibacterial activity of Origanum majorana L. essential oil from the Venezuelan Andes. Journal of Essential Oil Research 23(5): 45-49.

Rezaeih KAP, Gurbuz B, Uyanik M, Rahimi A, Arslan N (2015). Volatile constituents variability in Matricaria chamomilla L. from Ankara, Turkey. Journal of Essential Oil Bearing Plants 18(1): 255260.

Senatore F, Formisano C, Grassia A, Rigano D, Bellone G, Bruno M (2005). Chemical composition of the essential oil of Phagnalon saxatile (L.) Cass. (Asteraceae) growing wild in Southern Italy. Journal of Essential Oil Bearing Plants 8(3): 258-263.

Sînâ AB. Al-Qânûn Fi'l-Tibb (1998). Volume 2, English translation by H.A. Hameed and S.W. Nawab, Senior Press Superintendent, Jamia Hamdard Printing Press, New Delhi, India.

Siracusa L, Kulisic-Bilusic T, Politeo O, Krause I, Dejanovic B, Ruberto G (2011). Phenolic composition and antioxidant activity of aqueous infusions from
Capparis spinosa L. and Crithmum maritimum L. before and after submission to a two-step in vitro digestion model. Journal of Agricultural and Food Chemistry 59: 12453-12459.

Solak MH, Işıloğlu M, Kalmis E, Alli H (2015). Macrofungi of TURKEY Checklist Volume-II. Üniversiteliler Ofset, Bornova-İzmir-TR; ISBN: 978-605-030035-2.

Stanojevic LP, Marjanovic-Balaban ZR, Kalaba VD, Stanojevic JS, Cvetkovic DJ (2016). Chemical composition, antioxidant and antimicrobial activity of chamomile flowers essential oil (Matricaria chamomilla L.). Journal of Essential Oil Bearing Plants 19(8): 2017-2028.

Suppakul P, Miltz J, Sonneveld K, Bigger SW (2003). Antimicrobial properties of basil and its possible application in food packaging. Journal of Agricultural and Food Chemistry 51: 3197-3207.

Tlili N, Elfalleh W, Saadaoui E, Khaldi A, Triki S, Nasri N (2011). The caper (Capparis L.): Ethnopharmacology, phytochemical and pharmacological properties. Fitoterapia 82: 93-101.

Zambonelli A, D'Aulerio AZ, Severi A, Benvenuti S, Maggi L, Bianchi A (2004). Chemical composition and fungicidal activity of commercial essential oils of Thymus vulgaris L. Journal of Essential Oil Research 16(1): 69-74.

\section{How to cite this article:}

Nejdet Gültepe, Somia M.I. Bufrag, Ibtesam R.A. Abughadyra, Kamla A.O. Mohammed and Saleh B.A. Alkhunni. 2019. Comparison of Some Medicinal Plants and Macrofungi Essential Oil Components for Antimicrobial Activity against the Human and Fish Pathogens. Int.J.Curr.Microbiol.App.Sci. 8(11): 458-473. doi: https://doi.org/10.20546/ijcmas.2019.811.057 